\title{
Modulation of anti-inflammatory response in lipopolysaccharide stimulated human THP-1 cell line and mouse model at gene expression level with indigenous putative probiotic lactobacilli
}

\author{
V. Aparna Sudhakaran · Harsh Panwar · Ritu Chauhan • \\ Raj Kumar Duary • Rahul Kumar Rathore • \\ Virender Kumar Batish · Sunita Grover
}

Received: 23 January 2013/ Accepted: 21 May 2013/Published online: 2 June 2013

(C) Springer-Verlag Berlin Heidelberg 2013

\begin{abstract}
The anti-inflammatory potential of eight indigenous probiotic Lactobacillus isolates was evaluated in vitro in terms of modulating the expression of tumor necrosis factor-alpha (TNF- $\alpha$ ) and interleukin-6 (IL-6) in human acute monocytic leukemia (THP-1) cells under inflammatory conditions. Amongst these, Lactobacillus plantarum Lp91 was the most potent anti-inflammatory strain as it evoked a significant $(P<0.001)$ down-regulation of TNF- $\alpha$ by -1.45 -fold relative to the control in THP1 cells. However, in terms of IL-6 expression, all the strains could up-regulate its expression considerably at different levels. Hence, based on in vitro expression of TNF- $\alpha$, Lp91 was selected for in vivo study in lipopolysaccharide (LPS)induced mouse model to look at the expression of TNF- $\alpha$, IL-6, monocyte chemotactic protein-1 (MCP-1), vascular cell adhesion molecule-1 (VCAM-1), intercellular adhesion molecule (ICAM-1) and E-selectin in mouse aorta. In LPS challenged $(2 \mathrm{~h})$ mice group fed with Lp91 for 10 days, TNF- $\alpha$, IL-6, MCP-1, VCAM-1, ICAM-1 and E-selectin expressions were significantly down-regulated by 3.10-, 10.02-, 4.22-, -3.14-, 2.28- and 5.71-fold relative to control conditions. In conclusion, Lp91 could serve as a
\end{abstract}

Electronic supplementary material The online version of this article (doi:10.1007/s12263-013-0347-5) contains supplementary material, which is available to authorized users.

V. Aparna Sudhakaran · H. Panwar · R. Chauhan .

R. K. Rathore · V. K. Batish · S. Grover $(\bowtie)$

Department of Dairy Microbiology, Molecular Biology Unit,

National Dairy Research Institute, Karnal 132001,

Haryana, India

e-mail: sungro@gmail.com

R. K. Duary

Department of Food Engineering and Technology,

Tezpur University, Napaam 784028, Assam, India candidate probiotic strain to explore it as a possible biotherapeutic anti-inflammatory agent against inflammatory diseases including cardiovascular disease.

Keywords Probiotic - Lipopolysaccharide · Cardiovascular diseases - Intercellular adhesion molecule . Monocyte chemotactic protein-1 - Vascular cell adhesion molecule-1

\section{Introduction}

Therapeutic action of probiotics on the host's immune system has entered a new and fascinating phase of intensive research in quest for finding novel dietary anti-inflammatory agents. The prospects of exploring the anti-inflammatory efficacy of probiotic treatment against inflammatory disorders as well as metabolic syndrome like obesity, diabetes mellitus (DM-2) and cardiovascular diseases (CVDs) have made these food grade organisms with generally regarded as safe (GRAS) status a very attractive key microbial ingredient of functional and health foods specifically targeted in the management of anti-inflammatory disorders across the world (Martin et al. 2008; Hormannsperger and Haller 2010). Recent advancements in molecular biology and better understanding of the pathogenesis of several inflammatory conditions have facilitated scientists to delve deeper into the fundamental causes of metabolic disorders commonly associated with an age-old immunological defense mechanism, that is, inflammation.

Most of the time, inflammation acts as a life savior providing defense against various antigens. However, recent studies have shown that it could be fatal under extreme conditions. Excessive inflammation destabilizes cholesterol deposits in the coronary arteries, leading to 
heart attacks and even strokes (Laugerette et al. 2011) and hence can play a central role in the pathogenesis of heart diseases. The biochemical processes involved in CVDs are the same as those involved in blood coagulation, inflammation and immune response (Lapara and Kelly 2010). In other words, chronic inflammation may be the engine that drives many of the most feared illnesses of middle and old age, that is, CVDs and strokes.

Chronic low-grade inflammation is now recognized as one of the root causes for the onset of CVDs. The bacterial products specifically lipopolysaccharide (LPS) induce an inflammatory response, which is central to the pathophysiology of CVD and diabetes and provides a link between diseases of the gut and the vasculature (Harris et al. 2012). Scientific evidence has suggested that metabolic endotoxemia (LPS, 50-100 pg/ml) can cause chronic low-grade inflammation and mild disturbances in energy metabolism implicated in the development of CVD and type 2 diabetes (Maitra et al. 2011). Metabolic endotoxemia has been linked to the development of CVD as well. In a 5-year epidemiological study involving 516 middleaged men and women, those with plasma LPS levels over $50 \mathrm{pg} / \mathrm{ml}$ had a threefold increase in risk of developing atherosclerosis, while the subpopulation of smokers or exsmokers with the same level of LPS had a 13-fold increase (Wiedermann et al. 1999). In this context, the contribution of inflammation from gut microbiota in pathogenesis of CVD may provide insight into new therapies to decrease disease risk.

Cytokines mediate and regulate the inflammatory responses through the involvement of pro- and antiinflammatory interleukins and adhesion molecules. The role of cytokines in the pathogenesis of CVDs is increasingly evident ever since the inflammatory mechanisms in atherosclerosis and heart failure were understood (Lapara and Kelly 2010). Adhesion molecules like intercellular adhesion molecule (ICAM), vascular cell adhesion molecule (VCAM) and E-selectin also play a pivotal role in atherosclerotic plaque formation. Inflammation disturbs the homeostasis existing between anti- and pro-inflammatory cytokines. The increased level of pro-inflammatory cytokines such as tumor necrosis factor-alpha (TNF- $\alpha$ ) and IL-6 increase the hepatic synthesis of acute phase proteins like fibrinogen, $\mathrm{C}$ reactive protein, adhesion molecules like VCAM-1, ICAM-1 and E-selectin, etc., along with concurrent decrease in the synthesis of high density lipoprotein (HDL). Previous studies have shown that the pro-inflammatory mediators, particularly $\mathrm{TNF}-\alpha$, can induce a procoagulant state on the surface of vascular endothelium and monocytes, down-regulating the protein $\mathrm{C}$ anticoagulant pathway and stimulating thrombin and fibrin formation. Therapeutic approaches that reduce the levels of proinflammatory biomarkers and address traditional risk factors are specifically important in preventing CVD and other potentially metabolic disorders (Paoletti et al. 2006).

Recent findings on probiotics as potential biotherapeutics have revealed that these friendly organisms have bright prospects by serving as innovative tools to alleviate intestinal inflammation, normalize gut mucosal dysfunction and down-regulate hypersensitivity reactions (Maslowski and Mackay 2011). Oral administration of probiotics can influence immune response by modulating cytokine profiles not only locally in the intestines, but also systemically (Meyer et al. 2007). The consumption of probiotics can help in decreasing the level of interleukin-6 (IL-6) which in turn leads to reduction in the fibrinogen level in the blood. Amongst the probiotics, the role of lactobacilli in reducing the fibrinogen and cholesterol levels in blood has been well documented (Li et al. 2009; Kumar et al. 2011). Probiotics are also known to markedly inhibit $\mathrm{TNF}-\alpha$ production by normal and inflamed mucosa. It has been shown that some probiotic organisms can modulate the expression of proand anti-inflammatory molecules both in vitro as well as in vivo in a strain-dependent manner (Habil et al. 2011).

The present study was aimed to primarily assess the anti-inflammatory properties of putative indigenous probiotic Lactobacillus plantarum (L. plantarum) strains both in vitro (THP-1) cells and in vivo (mouse model) under inflammatory conditions at gene expression level with the long-term objective of exploring these as biotherapeutics in the management of inflammatory diseases including CVDs.

\section{Materials and methods}

\section{Bacterial strains}

Ten bacterial strains which included eight indigenous putative Lactobacillus isolates (L. plantarum 9, 21, 65, 75, 78, 91, 100 and L. pentosus S7) along with two reference strains viz. L. plantarum Lp5276 (also designated as CSCC5276, NCDO82 or VTTE-71034 was procured from Dr. N. P. Shah from Victoria University, Australia; Crittenden et al. 2002; Kaushik et al. 2009) and Lactobacillus acidophilus NCFM (also known as Howaru Dophilus, La-1, NCK56, NCK45, N2, RL8KR, RL8KS and RL8K; Sanders and Klaenhammer 2001; Altermann et al. 2005; Ringel-Kulka et al. 2011), the subject of this study, were procured from the probiotic culture collection maintained at Molecular Biology Unit, Dairy Microbiology Division, National Dairy Research Institute, Karnal. L. plantarum Lp91 was deposited at Microbial Type Culture Collection, Institute of Microbial Technology, Chandigarh, India, as MTCC 5690. The two reference strains of probiotic lactobacilli, that is, Lp5276 and NCFM were included in the study to compare the anti-inflammatory efficacy of the 
indigenous probiotic strains with that of reference strains to associate any variability in their purported functionality within L. plantarum or between Lactobacillus spp. Bacterial strains were activated prior to use by growing in de Man Rogosa Sharpe (MRS) broth (HiMedia, India) at $37{ }^{\circ} \mathrm{C}$ for $18-24 \mathrm{~h}$. The identity of the L. plantarum strains was ascertained by PCR both at genus and species level using genus-specific LbLMA1/R-161 (5'-ctc aaa act aaa caa agt ttc- $3^{\prime} / 5^{\prime}$-ctt gta cac acc gcc cgt tca-3') (Dubernet et al. 2002) and species-specific Lpla2/Lpla3 primers $\left(5^{\prime}-\right.$ att cat agt cta gtt gga ggt- $3^{\prime} / 5^{\prime}$-cet gaa ctg aga gaa tt ga- $3^{\prime}$ ) (Song et al. 2000) and was further authenticated by $16 \mathrm{~S}$ rDNA sequencing as described previously (Kaushik et al. 2009). In brief, the genomic DNA of Lactobacillus strains was isolated as per Pospiech and Neumann (1995). PCR was set up in a $25 \mu \mathrm{l}$ reaction volume containing sterile MilliQ water $(17 \mu \mathrm{l})$, PCR Buffer $(2.5 \mu \mathrm{l})$, Primer $(2.0 \mu \mathrm{l})$, dNTPs $(2.0 \mu \mathrm{l}), 1.0 \mathrm{U}$ Taq DNA polymerase $(0.5 \mu \mathrm{l})$ and template $(1.0 \mu \mathrm{l})$. The PCR cycling parameters included an initial denaturation of $95^{\circ} \mathrm{C} / 5 \mathrm{~min}$, followed by 45 cycles each of denaturation $\left(95^{\circ} \mathrm{C} / 30 \mathrm{~s}\right)$, annealing at $\left(55^{\circ} \mathrm{C} / 30 \mathrm{~s}\right)$ for genus-specific and $60{ }^{\circ} \mathrm{C} / 30 \mathrm{~s}$. for species-specific PCR followed by extension $\left(72{ }^{\circ} \mathrm{C} / 2 \mathrm{~min}\right)$ and final extension of $72{ }^{\circ} \mathrm{C} / 10 \mathrm{~min}$. The PCR products were electrophoresed on 1.8-2 \% agarose gel containing ethidium bromide and visualized under UV light (Fotodyne, USA).

Propagation of human acute monocytic leukemia cell line (THP-1)

Human acute monocytic leukemia cell line (THP-1) was procured from National Centre of Cell Sciences (NCCS, Pune, India). The cell line was cultured in Roswell Park Memorial Institute Medium 1640 (RPMI, Sigma, USA). The medium was supplemented with $10 \%$ (v/v) heat inactivated fetal bovine serum (Sigma, USA), $2 \mathrm{mM}$ glutamine (Sigma, USA), $1 \mathrm{mM}$ sodium pyruvate, $2 \mathrm{~g} / 1$ sodium bicarbonate, $0.05 \mathrm{mM}$ mercaptoethanol, $1 \%$ $100 \mathrm{U} / \mathrm{ml}$ penicillin (Sigma, USA) and $1 \% 100 \mathrm{U} / \mathrm{ml}$ streptomycin (Sigma, USA) in $25-\mathrm{cm}^{2}$ culture flask (Falcon, Beckton Dickinson, Sparks, MD, USA) and incubated at $37{ }^{\circ} \mathrm{C}$ in an atmosphere of $5 \% \mathrm{CO}_{2}$. The culture was passaged in fresh medium every alternate day for activation.

THP-1 cells were treated with phorbol 13 myristate 12 acetate (PMA) to convert it to THP-1 macrophage attached cell line. After attaining $80 \%$ confluency, $1 \times 10^{6}$ of cells $/ \mathrm{ml}$ were seeded in each well of the plates with complete medium and incubated at $37{ }^{\circ} \mathrm{C}$ under $5 \% \mathrm{CO}_{2}$. The growth medium was changed every 2 days. THP- 1 derived macrophage cells were cultured until complete confluency had reached. One day prior to challenging the cell line with probiotic Lactobacillus strains, the complete medium was replaced with basal medium free from serum and antibiotics. Viability of
THP-1 cells was assessed by trypan blue assay (dye exclusion method). The assay was used for determining the concentration of LPS (Escherichia coli; Sigma, USA) used for challenging the cell line. In brief, the cell suspension (about $10^{6}$ cells $\left./ \mathrm{ml}\right)$ was diluted in 1:1 ratio using a $0.2 \%(\mathrm{w} / \mathrm{v})$ trypan blue solution in saline water (mix 4 parts of $0.2 \%$ trypan blue with 1 part of $5 \times$ Saline $(4.25 \% \mathrm{NaCl} w / v)$. After incubation of $2 \mathrm{~min}$ at $37{ }^{\circ} \mathrm{C}$ under $5 \% \mathrm{CO}_{2}$, the cells were counted using hemocytometer and cell viability was calculated (viable cells will appear colorless). The viability of cell line at different concentrations of LPS was more than $95 \%$ at $100 \mathrm{ng} / \mathrm{ml}$ LPS for $3 \mathrm{~h}$ based on trypan blue exclusion assay.

Subjecting THP-1 macrophage cells with probiotics and LPS treatments

The THP-1 derived macrophages were separately prechallenged with each of the individual live probiotic Lactobacillus strains $\left[\sim 1 \times 10^{9}\right.$ colony forming unit $\left.(\mathrm{cfu}) / \mathrm{ml}\right]$ followed by LPS $(100 \mathrm{ng} / \mathrm{ml})$ treatment. Prior to challenge, the lactobacilli were grown $\mathrm{ON}$ in MRS broth at $37{ }^{\circ} \mathrm{C}$ and harvested by centrifugation at $5,500 \times g$ for $10 \mathrm{~min}$. The cells were then washed twice in PBS buffer, and $\mathrm{OD}_{600}$ was adjusted to 1.5 which corresponded to $\sim 1 \times 10^{9} \mathrm{cfu} / \mathrm{ml}$ based on viable plate count determination. The bacterial cells were then resuspended in RPMI $\left(\sim 1 \times 10^{9} \mathrm{cfu} / \mathrm{ml}\right)$. One $\mathrm{ml}$ of the cell suspension was then added to the wells of the culture plate and incubated at $37{ }^{\circ} \mathrm{C}$ in $5 \% \mathrm{CO}_{2}$ for $4 \mathrm{~h}$ followed by addition of fresh medium without antibiotic and fetal bovine serum.

After incubation, cells were challenged with $100 \mathrm{ng} / \mathrm{ml}$ LPS and again incubated further for $3 \mathrm{~h}$. LPS was completely removed by decanting the medium, and trypsinization was done by addition of trypsin-EDTA solution (Sigma, USA). Cells were centrifuged at $450 \times \mathrm{g} / 5 \mathrm{~min}$ at RT and resuspended in RPMI medium and pelleted. RNA was isolated from the cell pellet by TRIzol method (TRI Reagent Sigma, USA). One $\mu \mathrm{g}$ of the DNaseI (Promega, USA)-treated RNA was transcribed into cDNA, using ImPromII reverse transcriptase kit (Promega, USA) and random hexamer primers $(10 \mu \mathrm{M})$ provided with the same. The expression of pro-inflammatory cytokines like TNF- $\alpha$ and IL-6 was analyzed by RT-qPCR. Untreated THP-1 cells grown in RPMI served as control.

In vivo study using LPS mouse model

A total of 32 adult male (7-8 weeks old) Swiss Albino mice weighing 25-30 g on average were used in this study. The animals were fed normal diet (bengal gram crushed: $58 \%$, wheat starch: $15 \%$, groundnut cake: $10 \%$, casein: $4 \%$, groundnut oil: $4 \%$, salt mixture: $4 \%$, vitamin 
mixture: $0.2 \%$ and choline chloride: $0.2 \%$ ) and water ad libitum during the entire course of the experiment. The animals were divided into four homogeneous groups (LPS, Lp91 + LPS, control and Lp91 groups) comprising of eight animals each, housed in individual cages and maintained under a constant 12-h light-12-h dark cycle. The temperature was controlled at $21{ }^{\circ} \mathrm{C}$ with about 56-60\% relative humidity. Before conducting the animal trial, prior approval of the Institute's Animal Ethics Committee was obtained, and the mice were maintained as per National Institute of Nutrition, India, guidelines for the care and use of laboratory animals.

Feeding of mice and experimental design

The cell suspension of Lp91 $\left(10^{9} \mathrm{cfu} / \mathrm{ml}\right)$ was prepared by centrifuging $1.5 \mathrm{ml}$ of the $\mathrm{ON}$ grown culture $[4,000 \times g$, $15 \mathrm{~min}$ ] and resuspending the cell pellet in $200 \mu \mathrm{l}$ of sterile PBS. The mice were fed for 10 days by oral intubation of the cell suspension with the help of $1 \mathrm{ml}$ syringe and silicon tubing. The mice fed with PBS alone served as the control group. The experimental design has been illustrated in Fig. 1S under supplementary information. After fasting on 10th day, intraperitoneal injection of LPS $(20 \mathrm{mg} / \mathrm{kg}$ body weight) was given to mice $2 \mathrm{~h}$ before dissection on 11th day to induce inflammation. Aorta was collected during dissection. RNA was isolated from the aorta of mice under different experimental conditions by TriZol method. The DNase I (Promega, USA)-treated RNA was transcribed into cDNA, using Fermentas first strand cDNA synthesis kit with $100 \mu \mathrm{M}$ random hexamer primers. The expression of various pro-inflammatory cytokines like TNF- $\alpha$ and IL-6, chemokine MCP-1, VCAM-1, ICAM-1 and E-selectin after administration of Lp91 for 10 days was investigated by RT-qPCR.

\section{Relative gene expression studies by RT-qPCR}

The sequences of primers used in this study and their annealing temperature are given in Table 1 . $\beta$-Actin and actin-beta (ACTB) were the house-keeping genes for THP-1 cells and ACTB mouse aorta, respectively.

RT-qPCRs were set up in LightCycler 480 (Roche, Switzerland) preloaded with relative quantification software (version LCS480 1.5.0.39, Roche) along with fluorescence signal detection (SYBR Green). Each reaction was performed in a $10 \mu \mathrm{l}$ reaction volume containing $5 \mu \mathrm{l}$ of $2 \times$ SYBR Green PCR Master Mix (Roche), $2.5 \mu$ of properly diluted cDNA (30 $\mathrm{ng} / \mu \mathrm{l}$ of cDNA for all the genes used for RT-qPCR), $0.5 \mu \mathrm{l}$ of each primer at $10 \mu \mathrm{M}$ and $1.5 \mu \mathrm{l}$ of nuclease-free water. Negative controls (with no DNA template, only primer pair for the target genes, water and $2 \times$ SYBR Green PCR Master Mix) were included in each run. The thermal cycling conditions included initial denaturation at $95{ }^{\circ} \mathrm{C}$ for $5 \mathrm{~min}$, followed by 45 cycles each of denaturation $\left(95^{\circ} \mathrm{C} / 10 \mathrm{~s}\right)$, annealing (58-60/15 s) and extension $\left(15 \mathrm{~s}\right.$ at $72{ }^{\circ} \mathrm{C}$ with a single fluorescence measurement), a melt curve program $\left(60-95{ }^{\circ} \mathrm{C}\right.$ with a heating rate of $0.11^{\circ} \mathrm{C} / \mathrm{s}$ and continuous fluorescence measurement) and finally, a cooling step at $40{ }^{\circ} \mathrm{C}$. RNA extraction and measurement of gene expression by RT-qPCR were performed in triplicate, and the mean of all these values was used for final analysis.

Generation of quantitative data by real-time PCR is based on the number of cycles required for optimal amplification generated fluorescence to reach a specific threshold of detection (the quantification cycle; $C_{q}$ value) (Bustin et al. 2009). The relative expression ratios were calculated by a mathematical model, which included an efficiency correction for real-time PCR efficiency of the individual transcripts (Pfaffl 2001) as follows:

$$
\begin{aligned}
\text { Ratio }= & \left(E_{\text {target }}\right)_{\text {target }}^{\Delta C_{q}}(\text { control } \\
& - \text { sample }) /\left(E_{\text {ref }}\right)_{\text {ref }}^{\Delta C_{q}}(\text { control }- \text { sample })
\end{aligned}
$$

The relative expression ratio of the target gene was computed based on its real-time PCR efficiencies $(E)$ and the crossing point difference $\left(\Delta C_{q}\right)$ for an unknown sample versus a control. Real-time PCR amplification efficiencies were determined for each set of primers with the slope of a linear regression model (Pfaffl et al. 2002). The cDNA samples were diluted at a range of 100, 50, 25, 5, 1 and $0.25 \mathrm{ng} / \mathrm{ml}$ and were used as RT-qPCR templates. The standard curves were generated by plotting the $\log$ cDNA values against $C_{q}$ values obtained over the range of dilutions. The slope of the curves was used to determine the reaction efficiency $(E)$ as $E=10^{[-1 / \text { slope }]}$ (Rasmussen 2001). The total expression ratio was tested for significance by a randomization test implemented in the relative expression software tool (REST 2009) (www.genequantification.info) (Pfaffl et al. 2002). The integrated randomization and bootstrapping methods used in this software test the statistical significance of calculated expression ratios (either up- or down-regulations).

\section{Results}

The identity of bacterial isolates used in this study as L. plantarum was ascertained by both genus- and speciesspecific PCR (Fig. 2S) and further authenticated by $16 \mathrm{~S}$ rDNA sequencing. As the specific health promoting functions of probiotics are highly strain specific, attempts were also made to discriminate eight of the putative indigenous isolates of probiotic L. plantarum/Lactobacillus pestosus as distinct strains based on their unique RAPD banding patterns by RAPD PCR using three different random primers viz. 228, 244 and 275 (Fig. 3S). However, the most 
Table 1 Sequences of the primers used for RT-qPCR

\begin{tabular}{|c|c|c|c|c|}
\hline Genes & Primer sequence $\left(5^{\prime}-3^{\prime}\right)$ & $\begin{array}{l}\text { Annealing } \\
\text { temperature }\left({ }^{\circ} \mathrm{C}\right)\end{array}$ & $\begin{array}{l}\text { Amplicon } \\
\text { size (bp) }\end{array}$ & References \\
\hline TNF- $\alpha$ Sae F & agc cca tgt tgt agc aaa cc & 58 & 134 & Saegusa et al. (2007) \\
\hline TNF- $\alpha$ Sae R & tga ggt aca ggc cct ctg at & & & \\
\hline IL-6 Tatjana F & ttc aat gag gag act tgc ctg & 60 & 349 & Faruqi et al. (2001) \\
\hline IL-6 Tatjana R & aca aca aca atc tga ggt gcc & & & \\
\hline$\beta$-Actin F & $\operatorname{tgg}$ ctg ggg tgt tga agg tct & 58 & 238 & Lallemant et al. (2009) \\
\hline$\beta$-Actin $\mathrm{R}$ & agc acg gca tcg tca cca act & & & \\
\hline TNF- $\alpha$ mus $F$ & tct cat cag ttc tat ggc cc & 54 & 212 & Dombrowicz et al. (2001) \\
\hline TNF- $\alpha$ mus $\mathrm{R}$ & ggg act aga caa ggt aca ac & & & \\
\hline IL-6 mus F & gtt ctc tgg gaa atc gtg ga & 54 & 209 & Dombrowicz et al. (2001) \\
\hline IL-6 mus R & tgt act cca ggt agc tat gg & & & \\
\hline MCP-1 mus F & tct ggg cct gct gtt cac & 54 & 96 & This study \\
\hline MCP-1 mus $\mathrm{R}$ & gtg aat gag tag cag cag gtg agt & & & \\
\hline VCAM-1MF1 & $\operatorname{tgg}$ tga aat gga atc tga acc & 54 & 86 & This study \\
\hline VCAM-1MR1 & $\operatorname{ccc}$ aga tgg tgg ttt cet $t$ & & & \\
\hline ICAM-1MF1 & gga cca cgg agc caa ttt c & 55 & 82 & This study \\
\hline ICAM-1MR1 & ctc gga gac att aga gaa caa tgc & & & \\
\hline E-selectin MF & cce tge cca cgg tat cag & 55 & 85 & This study \\
\hline E-selectin MR & cce ttc cac aca gtc aaa cgt & & & \\
\hline $\mathrm{ACTB}$ mus $2 \mathrm{~F}$ & agt gtg acg ttg aca tcc gta & 54 & 112 & This study \\
\hline ACTB mus2R & gcc aga gca gta atc tcc ttc $t$ & & & \\
\hline
\end{tabular}

discriminatory random primer turned out to be 275 which led to development of distinct RAPD banding patterns by producing amplicons ranging in size from 100 to $2,000 \mathrm{bp}$.

Relative expression of TNF- $\alpha$ and IL-6 in THP-1 cells by RT-qPCR

In order to assess the immuno-modulatory efficacy of putative indigenous probiotic strains used in this study, the relative expression of the two key cytokines TNF- $\alpha$ and IL-6 in THP-1 cells induced with these strains was investigated by RT-qPCR. Specificity, linearity and efficiencies $(E)$ of primers for the target and reference genes used in RT-qPCR assay were ascertained as can be evidenced from the data presented under supplementary information (Figs. 4S, 5S). LPS was able to induce the expression of TNF- $\alpha$ significantly $(P<0.001)$ in THP-1 cells by 3.35 -fold (Figs. $1,6 \mathrm{~S})$. However, on pre-treatment of THP-1 cells with probiotics followed by LPS challenge evoked a varied response in terms of TNF- $\alpha$ expression. Out of the 10 probiotic strains used in this study, Lp9, Lp78, Lp91 and NCFM brought about a significant $(P<0.001)$ down-regulation of TNF- $\alpha$ expression by $-1.34-,-1.34-,-1.45-$ and -1.21 -fold, respectively, relative to the control. Contrary to this, Lp65 induced a significant $(P<0.001)$ up-regulation of TNF- $\alpha$ (2.20-fold). The probiotic strains Lp21, 75, 100 and S7, however, did not evoke any significant response in TNF- $\alpha$ expression.
Similarly, challenge of THP-1 cells with LPS alone induced the expression of IL- 6 significantly $(P<0.001)$ by 5.67-fold relative to control. However, probiotic treatment individually with Lp65, 9, 21 and 75 led to a significant $(P<0.001)$ increase in the expression of IL-6 by $78.91-$, 58.84-, 33.56- and 32.49-fold, respectively, in THP-1 cells. Contrary to this, the two reference strains Lp5276 and NCFM behaved differently with regard to IL-6 expression as Lp5276 evoked the expression of the same by 1.54-fold only as against 8.41-fold induced by NCFM, thereby, indicating that immune-modulatory effect of probiotics was strain dependent. Lp91 was chosen as the most potent strain for in vivo studies because of its ability to downregulate $\mathrm{TNF}-\alpha$ expression significantly by -1.45 -fold and also because this strain exhibited strong probiotic attributes and demonstrated cholesterol lowering effects as reported previously in our laboratory (Duary et al. 2010, 2011, 2012a, b; Kumar et al. 2011, 2012) for pursuing in vivo studies.

Relative expression of TNF- $\alpha$ and IL-6 in LPS mouse model by RT-qPCR

The specificity, linearity and efficiencies $(E)$ of the reference and target genes used in LPS mouse model were evaluated (Figs. 7S, 8S). The relative fold expression of TNF- $\alpha$ and IL-6 in mouse model (Figs. 2, 9S) indicates that 
Fig. 1 Relative expression of TNF- $\alpha$ and IL-6 in THP-1 cells. $U P$ up-regulated, $P(H I)$ probability of alternate hypothesis that difference between sample and control groups is due only to chance, $N S D$ no significant difference from control (gene expression measurement with regard to each RNA extractions from THP-1 cells was obtained in triplicate, and the mean of these values was used for further analysis)

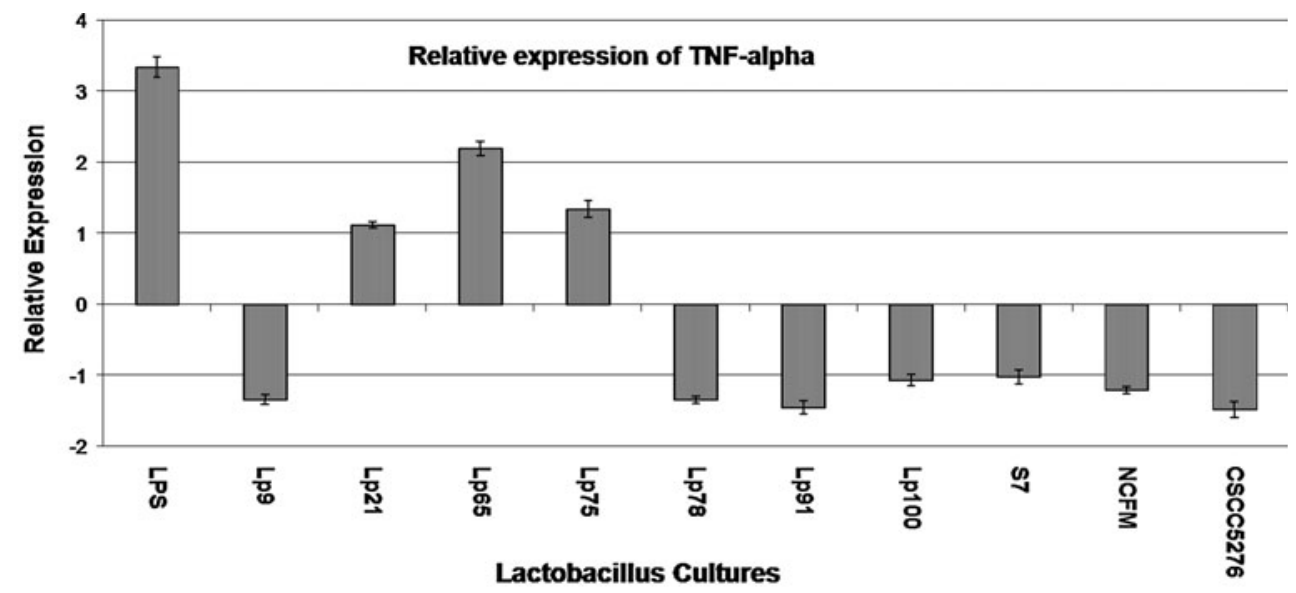

Relative fold change in expression of IL-6

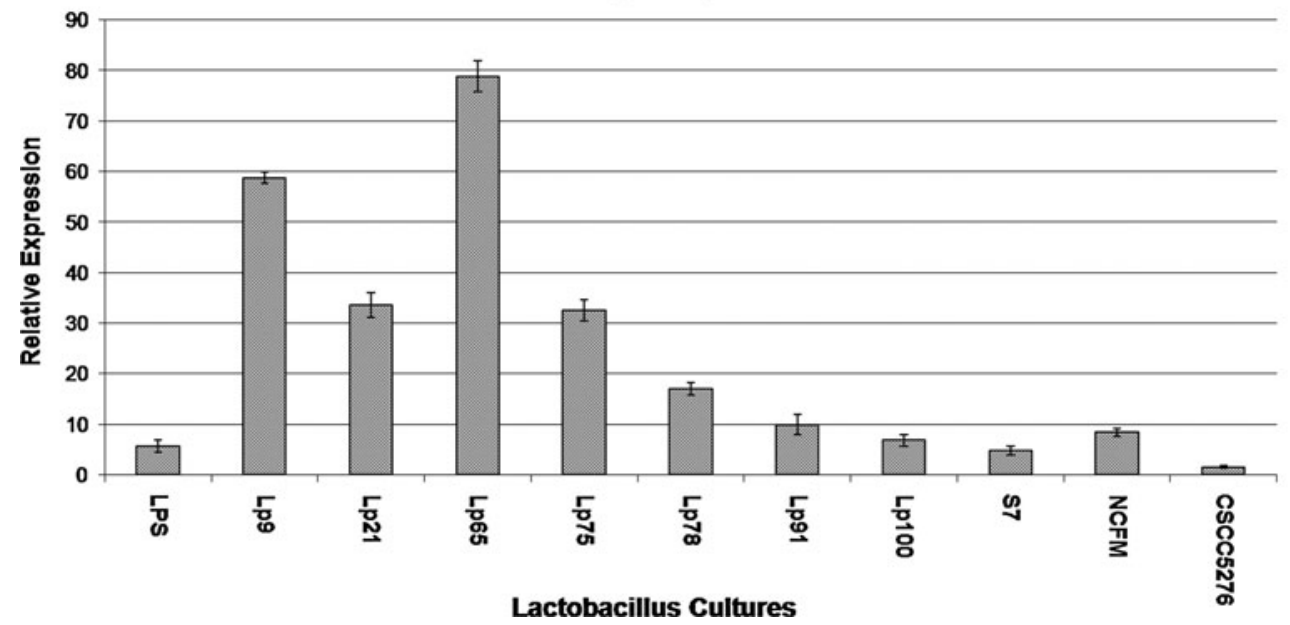

the expression of TNF- $\alpha$ was significantly $(P<0.001)$ upregulated at the level of 4.61-fold in aorta in LPS control mice group. Although the Lp91 treatment for 10 days in LPS mouse model led to a significant $(P<0.049)$ upregulation in the level of expression of TNF- $\alpha$ by 3.10-fold relative to untreated control group, there was actually a 1.51 -fold decrease in the level of expression of TNF- $\alpha$ as compared to LPS control. Similarly, LPS treatment was able to up-regulate the expression of IL-6 in mice significantly $(P<0.001)$ at the level of 32.33 -fold in comparison with control. However, treatment with Lp91 for 10 days in LPS mice group resulted again into a significant $(P<$ 0.001 ) increase in the expression of IL- 6 by 10.02 -fold relative to control in aorta. In this case also, there was in fact a 22.31-fold reduction (from 32.33 to 10.02) in the expression of IL-6 as compared to LPS as control.

Relative expression of MCP-1, VCAM-1, ICAM-1 and E-selectin

The relative expression of MCP-1 along with VCAM-1, ICAM-1 and E-selectin has been recorded in Whisker box plots (Fig. 10S) and Bar diagrams in Fig. 3. LPS treatment induced the expression of MCP-1 significantly $(P<0.030)$ at the level of 4.94-fold relative to control, whereas the treatment with Lp91 evoked 4.22-fold expression, thereby, leading to an overall 0.73 -fold decrease in the level of expression as compared to LPS control. Contrary to this, administration of Lp91 alone in mice ended up into a significant down-regulation of MCP-1 expression significantly $(P<0.027)$ by -2.40 -fold in comparison with upregulation of the same in Lp91-fed mice group after LPS treatment.

With regard to VCAM-1 and ICAM-1, LPS stimulation showed a significant up-regulation of the two genes $(P<0.037)$ in mice by 2.94 - and 8.22 -folds, respectively, relative to control group. However, treatment with Lp91 along with LPS resulted into a significant down-regulation of VCAM-1 to -3.14-fold as compared to LPS control. Contrary to this, under the same conditions, ICAM-1 expression was up-regulated significantly $(P<0.045)$ with relative increase of 2.28 -fold indicating a significant decrease of 5.95-fold in the level of ICAM-1 when compared to LPS group alone. However, there was a significant 


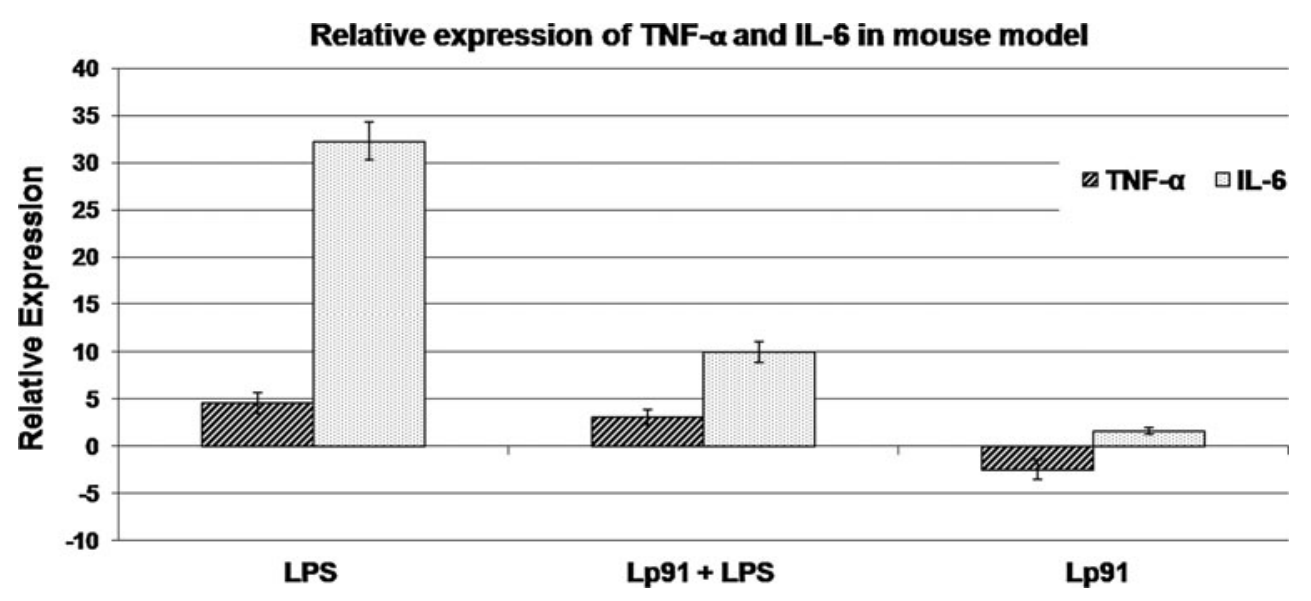

Fig. 2 Relative expression of TNF- $\alpha$ and IL-6 in LPS-induced mouse model. $U P$ up-regulated, $P(H I)$ Probability of alternate hypothesis that difference between sample and control groups is due only to chance, NSD no significant difference from control (gene expression measurement with regard to each RNA extractions from mouse aorta was obtained from four homogeneous groups (control, LPS + PBS, non-LPS + Lp91 and LPS + Lp91 groups) comprising of eight animals each $(n=8)$, and the mean of these values was used for analysis)
Fig. 3 Relative expression of MCP-1, VCAM-1, ICAM-1 and E-selectin in mouse model. $U P$ up-regulated, $P(H I)$ probability of alternate hypothesis that difference between sample and control groups is due only to chance, $N S D$ no significant difference from control (gene expression measurement with regard to each RNA extractions from mouse aorta was obtained from four homogeneous groups (control, LPS + PBS, nonLPS + Lp91 and LPS + Lp91 groups) comprising of eight animals each $(n=8)$, and the mean of these values was used for analysis)

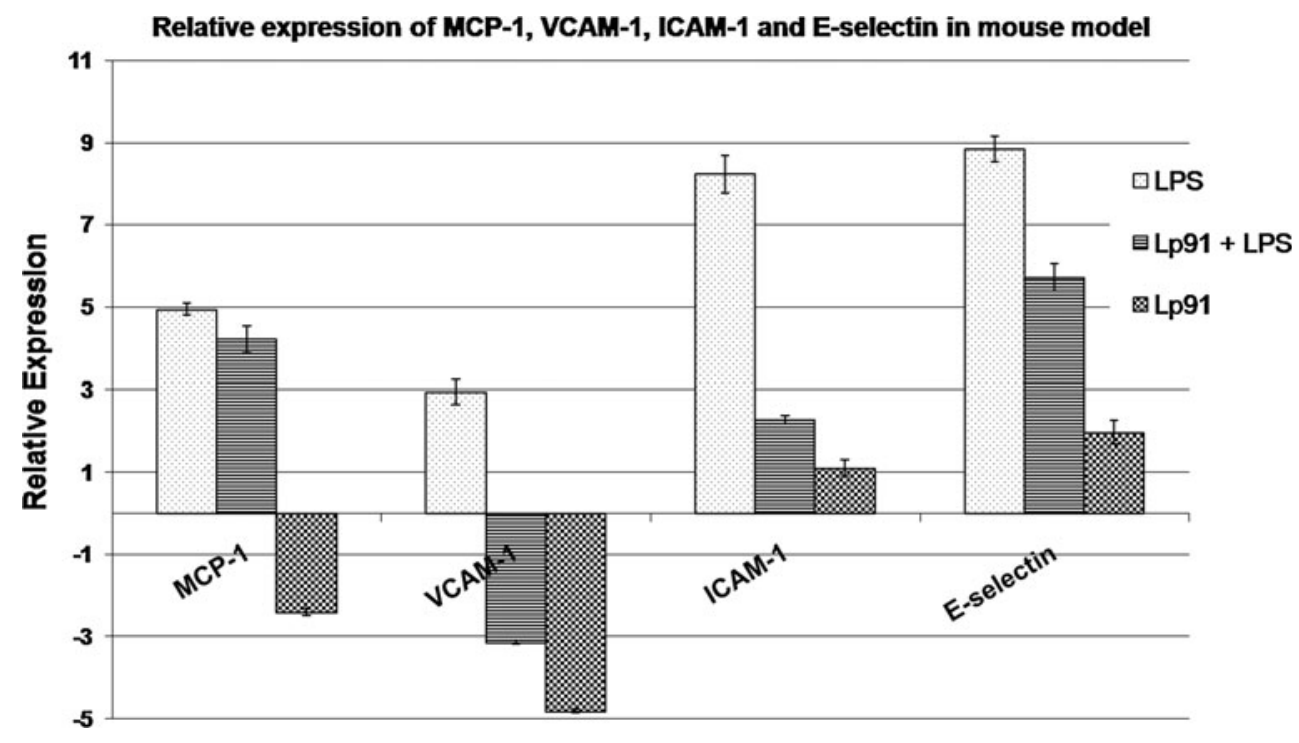

$(P<0.009)$ down-regulation of VCAM-1 by -4.81 -fold in case of mice group fed with Lp91 alone for 10 days, whereas expression of ICAM-1 in the same animal group was down-regulated by 1.09 -fold which, however, was non-significant.

LPS challenge led to expression of E-selectin in mice significantly $(P<0.002)$ by 8.84 -fold relative to control. However, in mice group wherein Lp91 was fed for 10 days followed by LPS challenge for $2 \mathrm{~h}$, there was a significant $(P<0.006)$ relative increase in E-selectin expression by 5.71-fold relative to control. These results further indicate that there was actually 3.13-fold reductions in the expression of E-selectin. On the other hand, when Lp91 was fed alone, there was no significant change in the level of E-selectin expression (1.97-fold).
Persistence of Lactobacillus plantarum 91 in mouse gut

The persistence of Lp91 in mouse model after feeding the same for 10 days could be reflected from shedding of Lp91 in fecal samples based on lactobacillus counts on MRS agar (Fig. 4) and their RAPD profiles (Fig. 11S). The persistence of Lp91 cells in mice fed with the same strain by oral intubation of $10^{9} \mathrm{cfu} / \mathrm{ml}$ for 10 days was determined by analyzing the fecal samples at $0,1,2,5,7$ and 10th day of the experimental trial. Initially, the total viable counts at the rate of $6.17 \mathrm{log} \mathrm{cfu} / \mathrm{ml}$ were recorded on first day which subsequently increased to $7.21 \log \mathrm{cfu} / \mathrm{ml}$ on 5 th day and to $8.50 \log \mathrm{cfu} / \mathrm{ml}$ on 10th day in LPS mice group. A gradual increase in the lactobacilli counts was recorded both in LPS and non-LPS mice groups along with probiotic 


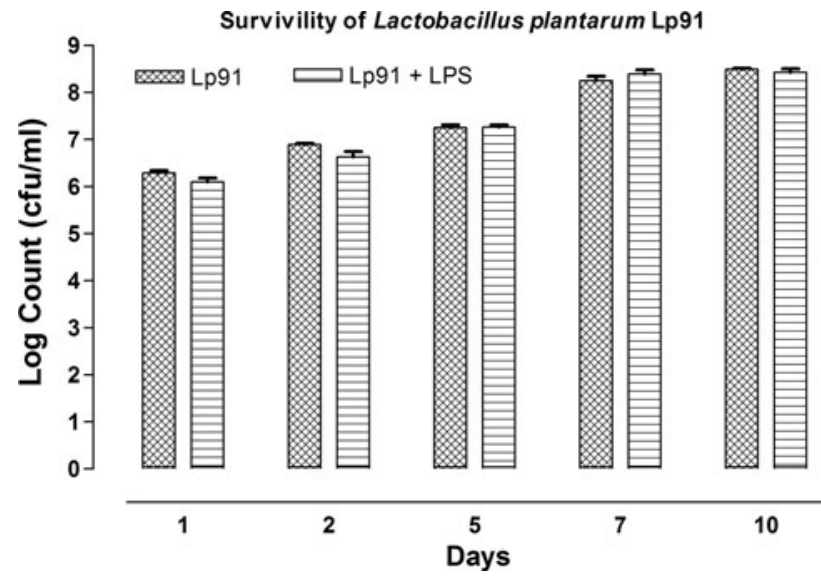

Fig. 4 Persistence of L. plantarum 91 (Lp91) in fecal samples of mouse

treatment indicating that the lactobacilli including the Lp91 could survive in colon in fairly good number to express their functions optimally.

\section{Discussion}

New insights into the pathogenesis of CVDs reveal that inflammation is the hallmark of atherosclerosis and takes place as a consequence of endogenous or exogenous insult of the vessel wall (Lapara and Kelly 2010). The progression of this inflammatory response is regulated by specific patterns of cytokine expression. The outcome of the study conducted by Gotsman et al. (2008) on the patients with atherosclerosis - a chronic inflammatory condition clearly demonstrated that the expression of inflammatory markers like IL-6 and tumor necrosis factor-alpha was increased significantly in those patients which eventually could end up into coronary artery diseases. Hence, the balance of pro- and anti-inflammatory cytokines is of considerable biological significance in vascular inflammation and is underscored by the fact that in vivo down-regulation of pro-inflammatory cytokines reduces atherogenesis. Because of their alleged role in inflammatory response, these pro-inflammatory cytokines were targeted in our study to look at their relative expression both in THP-1 cells and mouse model evoked with the test $L$. plantarum strains under inflammatory conditions.

In vitro studies

The results obtained from this study clearly demonstrate that the ability to modulate cytokine network particularly in terms of TNF- $\alpha$ expression by probiotic bacteria was highly strain specific. Several reports are available in literature on the immuno-stimulatory properties of probiotics for augmenting the expression of TNF- $\alpha$ (Cross et al. 2004; Mohamadzadeh et al. 2005), whereas an equivalent reports on inhibition of TNF- $\alpha$ expression evoked by probiotic strains are also available (Pena et al. 2005; Chan Remillard and Ozimek 2006; Lin et al. 2008). Morita et al. (2002) also reported that the immuno-regulatory activities of lactobacilli were highly strain dependent. Our results on down-regulation of TNF- $\alpha$ expression by probiotics are in agreement with the previous reports wherein the inhibition of TNF- $\alpha$ expression in intestinal cells isolated from Crohn's patients and LPS-activated THP-1 cells and human monocyte derived macrophages on treatment with specific probiotic strains was recorded (Carol et al. 2006; Lin et al. 2008; Jones and Versalovic 2009).

Probiotic cultures have clinical relevance for amelioration of inflammatory diseases such as CVDs, inflammatory bowel disease (IBD)/Crohn's disease (CD)/ulcerative colitis (UC), etc., as these patients have increased levels of TNF- $\alpha$ which needs to be reduced and hence these patients are given anti-TNF- $\alpha$ therapy. A large number of clinical studies using anti-TNF- $\alpha$ mAb (anti-tumor necrosis factoralpha monoclonal antibody) therapy have clearly shown a beneficial effect in IBD patients (Rutgeerts et al. 2004). Anti-TNF- $\alpha$ treatment can inhibit the cytokine-induced chain of events likely to result into increased risk of CVDs. The important role played by TNF- $\alpha$ in intestinal inflammation is strongly supported by the fact that drugs capable of interfering with the activity of this mediator are being developed for IBD therapy. Down-regulation of TNF- $\alpha$ can restore the breach of the innate immunity and thereby prevent the onset of the inflammatory events. In this context, our study clearly demonstrate the anti-inflammatory prospects of our putative probiotic lactobacilli strains by down-regulating the expression of TNF- $\alpha$ in THP-1 cells which can be eventually be explored in the management of inflammatory metabolic disorders. Our indigenous probiotic lactobacillus strains Lp91, 9 and 100 which were able to down-regulate TNF- $\alpha$ significantly could serve as the potential candidate probiotics for the management of inflammatory diseases including CVDs.

With regard to expression of IL-6 in THP-1 cells, it was observed from our study that probiotic treatment could enhance the expression of this dual function cytokine IL-6. It is a pleiotropic cytokine with dual functionality, that is, it has both pro-inflammatory as well as anti-inflammatory properties under different conditions (Lee et al. 2009; Xing et al. 1998). Our results in this context are in agreement with those of Reilly et al. (2007) who also reported that probiotic Lactobacillus paracasei could potentiate the effects of IL-1 $\beta$ on IL-6 production in cultured Caco- 2 cells suggesting its anti-inflammatory properties. However, our results are partially in agreement with the findings of Servin (2004) who reported that probiotic strains 
attenuated the production of IL- 6 , IFN- $\gamma$ and NO in the host cells. Furthermore, a study conducted by Xing et al. (1998) also clearly revealed an anti-inflammatory nature of IL-6 in both local and systemic acute inflammatory responses elicited by local lung or systemic exposure to endotoxin by using IL-6 gene knockout mice. It was demonstrated that IL- 6 was critically required to control the extent of local or systemic acute inflammatory responses, particularly the level of pro-inflammatory cytokines in the local and systemic compartments, respectively. The demonstration of these opposing effects in the host cells by different probiotics with regard to IL-6 expression could possibly be attributed to their strain specificity.

In vivo studies

As far as we understand, there is no direct published report available on the expression of TNF- $\alpha$ and IL- 6 in mouse aorta on LPS stimulation and probiotic treatment. Therefore, right now, we are not in a position to substantiate our results with the observations of other groups of workers on TNF- $\alpha$ and IL-6 expression in other affected tissues in inflammatory mouse models. Our findings in this regard are supported by the outcome of a similar study conducted by Perdigon et al. (2002) who also recorded significant dose-dependent increase in TNF- $\alpha$ values $(P<0.01)$ in the intestinal tissue with all LAB strains tested in mouse model. Kano et al. (2002) also reported that oral administration of milk fermented with Lactobacillus delbrueckii ssp. bulgaricus OLL1073R-1 into DBA/1 mice inhibited secretion of IL-6 and TNF- $\alpha$ by lymph node cells (LNC). Peran et al. (2005), on the other hand, reported highly diverse results with lactic acid bacteria on their ability to enhance or to reduce inflammatory cytokine production of TNF- $\alpha$. A decreased colonic expression of TNF- $\alpha$ by different LAB in colitis mouse model has also been reported (Arribas et al. 2009; Lee et al. 2009). Regarding the effect of probiotics on IL-6 expression, our results are consistent with the observations of Ruiz et al. (2005) who too reported that enterocytes could excrete cytokines such as IL-6 in presence of probiotic organisms as demonstrated with several physiological animal models. Similarly, Vinderola et al. (2005) also reported that intestinal epithelial cells could produce IL-6 up to 5 days on colonization with only one organism, that is, Bifidobacterium lactis $\mathrm{Bb}-12$ in rats. In a recent report, $L$. delbrueckii and Lactobacillus fermentum when given orally in moderate UC patients for 8 weeks significantly ameliorated inflammation by decreasing the colonic concentration of IL-6, expression of TNF- $\alpha$ and NF- $\mathrm{kBp} 65$ and leukocyte recruitment (Hegazy and El-Bedewy 2010). In a more recent study, Martins et al. (2011) reported that the pretreatment with Saccharomyces cerevisiae 905 orally decreased levels of pro-inflammatory cytokines (IL-6, IL-10, TGF- $\beta$, TNF- $\alpha$, and IFN- $\gamma$ ) in a murine model challenged with Salmonella typhimurium. However, our findings are at variance with those of Pavan et al. (2003) who recorded substantial increase in level of TNF- $\alpha$, IFN- $\gamma$ and IL-10 mRNA in the ilea and colons of mice on receiving a single daily dose of L. plantarum NCIMB8826 or Lactococcus lactis for 4 consecutive days. These differences related to gene expression might be attributed to strain specificity of the probiotic cultures used in their respective studies along with that of different animal models.

The validity of our results related to expression of MCP1 in mice evoked by probiotic interventions can be supported by almost similar findings recorded in some previous studies (Veckman et al. 2003; Ukena et al. 2005), wherein up- or down-regulation of the expression of MCP-1 in animal models and cell lines on probiotic treatment along with inflammatory agent was recorded. Later, Harata et al. (2010) demonstrated that intranasal administration of LGG led to significant increase in mRNA expression of IL-1 $\beta$, TNF- $\alpha$ and MCP-1 $(P<0.01)$ in an animal model. From these findings, it can be concluded that although lot of in vitro studies on MCP-1 expression induced by probiotic treatments have been conducted in different cell lines by different groups, there are hardly any in vivo studies that were attempted on similar lines.

Our findings with regard to relative expression of VCAM-1 and ICAM-1 induced in mice on probiotic treatment along with LPS can be adequately supported with a handful of studies carried out on similar lines. In one of the clinical studies conducted by Hilvak et al. (2005), it was reported that long-term (56 week) oral administration of probiotic Enterococcus faecium M-74 decreased the expression of sICAM-1 and monocyte CD54. It was notably found that plasma sICAM-1 level increased no sooner than 4 weeks when probiotic administration discontinued. In another in vivo study conducted in colitic rats by Angulo et al. (2006), it was demonstrated that Lactobacillus casei prevented the upregulation of ICAM-1 expression and leukocyte recruitment in experimental colitis. Endothelial ICAM-1 and VCAM-1 expression was significantly increased in the colonic endothelium in association with the induction of colitis. Our results on these aspects can be further supported by almost similar findings recorded by $\mathrm{Chu}$ et al. (2009) who also reported that $L$. plantarum treatment improved the histological damage score in IL-10 knockout (KO) mice compared to untreated $\mathrm{KO}$ mice and also significantly attenuated the expression of MAdCAM-1 and ICAM-1. Thus, our indigenous probiotic strain Lp91 could significantly down-regulate the expression of 
VCAM-1 and hence by virtue of having this attribute, it could be an attractive candidate probiotic to explore it as a potential biotherapeutic role in the management of inflammatory diseases including CVDs and other related diseases where such adhesion molecules could have a deleterious role by blocking the endothelial cells in the blood circulating system.

Similarly, as far as E-selectin is concerned, there is hardly any published report on its expression in the host cells on probiotic treatment. Nevertheless, some studies have been conducted, wherein phenolic compounds and herbal medicines have been reported to inhibit the expression of E-selectin (Carluccio et al. 2003; Hu et al. 2009). Hence, the useful information generated from the outcome of these studies related to the effect of phenolic compounds and herbal medicines could also be extrapolated to probiotic effect for modulating the expression of important adhesion molecules like E-selectin to establish their efficacy as biotherapeutics in the management of inflammatory diseases including CVDs and other heartrelated problems.

\section{Conclusions}

From the findings of this study, it can be concluded that our indigenous probiotic Lactobacillus strain Lp91 possessed strong anti-inflammatory property by virtue of its ability to down-regulate TNF- $\alpha$ expression in THP-1 cells and LPS mouse model. This strain is also adequately equipped with in built protective system with ability to inhibit the expression of key chemokine and adhesion molecules such as MCP-1, VCAM-1, ICAM-1 and E-selectin in mice under the inflammatory conditions. By modulating the expression of these key signal molecules having potential clinical implications in human health, Lp91 holds great promise and could serve as the perspective biotherapeutic agent in the management of inflammatory disorders particularly CVDs including atherosclerosis. These findings are likely to open new avenues for exploring anti-inflammatory properties of probiotics along with their ability to inhibit key adhesion molecules as a new weapon to target inflammatory disorders including CVDs.

\begin{abstract}
Acknowledgments We gratefully acknowledge the support provided by Director, National Dairy Research Institute (Karnal, India) and Indian Council of Agricultural Research (India) to carry out the study. The authors are also indebted to Ministry of Food Processing Industries (MoFPI) for financial support during the execution of the project. The authors also gratefully acknowledge the help rendered by Dr. Rajeev Kapila, Principal Scientist, Animal Biochemistry Division, Mr. Mohinder Singh, Attd., Small animal house, NDRI.
\end{abstract}

Conflict of interest The authors have declared no conflict of interest.

\section{References}

Altermann E, Russell WM, Azcarate-Peril MA, Barrangou R, Buck BL, McAuliffe O, Souther N, Dobson A, Duong T, Callanan M, Lick S, Hamrisk A, Cano R, Klaenhammer TR (2005) Complete genome sequence of the probiotic lactic acid bacterium Lactobacillus acidophilus NCFM. Proc Natl Acad Sci 102:3906-3912. doi:10.1073/pnas.0409188102

Angulo S, Llopis M, Antolin M, Gironella M, Sans M, Malagelada JR, Pique JM, Guarner F, Panes J (2006) Lactobacillus casei prevents the upregulation of ICAM-1 expression and leukocyte recruitment in experimental colitis. Am J Physiol Gastrointest Liver Physiol 291:G1155-G1162

Arribas B, Rodriguez-Cabezas ME, Camuesco D, Comalada M, Bailon E, Utrilla P, Nieto A, Concha A, Zarzuelo A, Galvez J (2009) Probiotic strain of Escherichia coli, Nissle 1917, given orally exerts local and systemic anti-inflammatory effects in lipopolysaccharide-induced sepsis in mice. $\mathrm{Br} \mathrm{J}$ Pharmacol 157:1024-1033

Bustin SA, Benes V, Garson JA, Hellemans J, Huggett J, Kubista M, Mueller R, Nolan T, Pfaffl MW, Shipley GL, Vandesompele J, Wittwer CT (2009) The MIQE guidelines: minimum information for publication of quantitative real-time pcr experiments. Clin Chem 55L:611-622

Carluccio MA, Siculella L, Ancora MA, Massaro M, Scoditti E, Storelli C, Visioli F, Distante A, De Caterina R (2003) Olive oil and red wine antioxidant polyphenols inhibit endothelial activation antiatherogenic properties of mediterranean diet phytochemicals. Arter Thromb Vasc Biol 23:622-629

Carol M, Borruel N, Antolin M, Llopis M, Casellas F, Guarner F, Malagelada JR (2006) Modulation of apoptosis in intestinal lymphocytes by a probiotic bacteria in Crohn's disease. J Leukoc Biol 79:917-922

Chan Remillard SKW, Ozimek L (2006) Inhibition of tumour necrosis factor by lactic acid bacteria in mouse macrophages. DRTC Dairy Day 45-46

Chu Z, Chen H, Ma Y, Zhou Y, Zhang M, Zhang P, Qin HL (2009) Lactobacillus plantarum prevents the upregulation of adhesion molecule expression in an experimental colitis model. Dig Dis Sci 55:2505-2513

Crittenden R, Karppinen S, Ojanen S, Tenkanen M, Fagerstrom R, Matto J, Saarela M, Mattila-Sandholm T, Poutanen K (2002) In vitro fermentation of cereal dietary fibre carbohydrates by probiotic and intestinal bacteria. J Sci Food Agric 82:781-789

Cross ML, Ganner A, Teilab D, Fray LM (2004) Patterns of cytokine induction by gram-positive and gram-negative probiotic bacteria. FEMS Immunol Med Microbiol 42:173-180

Dombrowicz D, Nutten S, Desreumaux P, Neut C, Torpier G, Peeters M, Colombel JF, Capron M (2001) Role of the high affinity immunoglobulin $\mathrm{E}$ receptor in bacterial translocation and intestinal inflammation. J Exp Med 193:25-34

Duary RK, Batish VK, Grover S (2010) Expression of atpD gene in putative indigenous probiotic $L$. plantarum strains under in vitro acidic conditions by RT-qPCR. Res Microbiol 161:399-405

Duary RK, Rajput YS, Batish VK, Grover S (2011) Assessing the adhesion of putative indigenous probiotic lactobacilli to human colonic epithelial cells. Indian J Med Res 134:664-671

Duary RK, Batish VK, Grover S (2012a) Relative gene expression of bile salt hydrolase and surface proteins in two putative indigenous Lactobacillus plantarum strains under in vitro gut conditions. Mol Biol Rep 39:2541-2552

Duary RK, Bhausaheb MA, Batish VK, Grover S (2012b) Antiinflammatory and immunomodulatory efficacy of indigenous probiotic Lactobacillus plantarum Lp91 in colitis mouse model. Mol Biol Rep 39:4765-4775 
Dubernet S, Desmasures N, Gueguen M (2002) A PCR based method for identification of lactobacilli at the genus level. FEMS Microbiol Lett 214:271-275

Faruqi TR, Gomez D, Bustelo XR, Bar-Sagi D, Reich NC (2001) Rac1 mediates STAT3 activation by autocrine IL-6. Proc Natl Acad Sci 98:9014-9019

Gotsman I, Stabholz A, Planer D, Pugatsch T, Lapidus L, Novikov Y, Masrawa S, Soskolne A, Lotan C (2008) Serum cytokine tumor necrosis factor-alpha and interleukin-6 associated with the severity of coronary artery disease: indicators of an active inflammatory burden? Isr Med Assoc J 10:494-498

Habil N, Al-Murrani W, Beal J, Foey AD (2011) Probiotic bacterial strains differentially modulate macrophage cytokine production in a strain-dependent and cell subset-specific manner. Benef Microbes 2:283-293

Harata G, He F, Hiruta N, Kawase M, Kubota A, Hiramatsu M, Yausi $\mathrm{H}$ (2010) Intranasal administration of Lactobacillus rhamnosus GG protects mice from H1N1 influenza virus infection by regulating respiratory immune responses. Lett Appl Microbiol 50:597-602

Harris K, Kassis A, Major G, Chou CJ (2012) Is the gut microbiota a new factor contributing to obesity and its metabolic disorders? J Obes 2012:14. doi:10.1155/2012/879151

Hegazy SK, El-Bedewy MM (2010) Effect of probiotics on proinflammatory cytokines and NF- $\mathrm{KB}$ activation in ulcerative colitis. World J Gastroenterol 16:4145-4151

Hilvak P, Jhanova E, Odraska J, Ferenick M, Ebringer L, Mikes Z (2005) Long term (56 week) oral administration of probiotic Enterococci faecium M-74 decreases the expression of sICAM-1 and monocyte CD54, and increases that of lymphocytes CD49d in humans. Bratisl Lek Listy 106:175-181

Hormannsperger G, Haller D (2010) Molecular crosstalk of probiotic bacteria with the intestinal immunesystem: clinical relevance in the context of inflammatory bowel disease. Int J Med Microbiol 300:63-73. doi:10.1016/j.ijmm.2009.08.006

Hu Y, Chen X, Duan H, Hu Y, Mu X (2009) Chinese herbal medicinal ingredients inhibit secretion of IL-6, IL-8, E-selectin and TXB2 in LPS-induced rat intestinal microvascular endothelial cells. Immunopharmacol Immunotoxicol 31:550-555

Jones SE, Versalovic J (2009) Probiotic Lactobacillus reuteri biofilms produce antimicrobial and anti-inflammatory factors. BMC Microbiol 9:35

Kano H, Mogami O, Uchida M (2002) Oral administration of milk fermented with Lactobacillus delbrueckii ssp. bulgaricus OLL1073R-1 to DBA/1 mice inhibits secretion of proinflammatory cytokines. Cytotechnology 40:67-73

Kaushik JK, Kumar A, Duary RK, Mohanty AK, Grover S, Batish VK (2009) Functional and probiotic attributes of an indigenous isolate of Lactobacillus plantarum. PLoS One 4:e8099. doi: 10.1371/journal.pone.0008099

Kumar R, Grover S, Batish VK (2011) Hypocholesterolaemic effect of dietary inclusion of two putative probiotic bile salt hydrolaseproducing Lactobacillus plantarum strains in Sprague-Dawley rats. Br J Nutr 105:561-573

Kumar R, Grover S, Batish VK (2012) Bile salt hydrolase (Bsh) activity screening of lactobacilli: in vitro selection of indigenous Lactobacillus strains with potential bile salt hydrolysing and cholesterollowering ability. Probiotics Antimicrob Prot 4:162-172

Lallemant B, Evrard A, Combescure C, Chapuis H, Chambon G, Raynal C, Reynaud C, Sabra O, Joubert D, Hollande F, Lallemant JG, Lumbroso S, Brouillet JP (2009) Reference gene selection for head and neck squamous cell carcinoma gene expression studies. BMC Mol Biol 10:78

Lapara NJ 3rd, Kelly BL (2010) Suppression of LPS-induced inflammatory responses in macrophages infected with Leishmania. J Inflamm (Lond) 7:8
Laugerette F, Vors C, Peretti N, Michalski M (2011) Complex links between dietary lipids, endogenous endotoxins and metabolic inflammation. Biochimie 93:39-45

Lee B, Lee JH, Lee HS, Bae EA, Huh CS, Ahn YT, Kim DH (2009) Glycosaminoglycan degradation-inhibitory lactic acid bacteria ameliorate 2,4,6-trinitrobenzenesulfonic acid-induced colitis in mice. J Microbiol Biotechnol 19:616-621

Li N, Russell WM, Douglas-escobar M, Hauser N, Lopez M, Neu J (2009) Live and heat-killed Lactobacillus rhamnosus GG: effects on pro-inflammatory and anti-inflammatory cytokines/ chemokines in gastrostomy-fed infant rats. Pediatr Res 66:203-207

Lin YP, Thibodeaux CH, Pena JA, Ferry GD, Versalovic J (2008) Probiotic Lactobacillus reuteri suppress pro inflammatory cytokine via c-Jun. Inflamm Bowel Dis 14:1068-1083

Maitra U, Gan L, Chang S, Li L (2011) Low-dose endotoxin induces inflammation by selectively removing nuclear receptors and activating ccaat/enhancer-binding protein $\delta$. J Immunol 86: 4467-4473

Martin P, Wang Y, Sprenger N, Yap IKS, Lundstedt T, Lek P, Rezzi S, Ramadan Z, van Bladeren P, Fay LB, Kochhar S, Lindon JC, Holmes E, Nicholson JK (2008) Probiotic modulation of symbiotic gut microbial-host metabolic interactions in a humanized microbiome mouse model. Mol Syst Biol 4:157. doi: $10.1038 / \mathrm{msb} 4100190$

Martins FS, Elian SD, Vieira AT, Tiago FC, Martins AK, Silva FC, Souza EL, Sousa LP, Araujo HR, Pimenta PF, Bonjardim CA, Arantes RM, Teixeira MM, Nicoli JR (2011) Oral treatment with Saccharomyces cerevisiae strain UFMG 905 modulates immune responses and interferes with signal pathways involved in the activation of inflammation in a murine model of typhoid fever. Int J Med Microbiol 301:359-364

Maslowski KM, Mackay CR (2011) Diet, gut microbiota and immune responses. Nat Immunol 12:5-9. doi:10.1038/ni0111-5

Meyer AL, Elmadfa I, Herbacek I, Micksche M (2007) Probiotic, as well as conventional yogurt, can enhance the stimulated production of proinflammatory cytokines. J Hum Nutr Diet 20:32-38

Mohamadzadeh M, Olson S, Kalina WV, Ruthel G, Demmin GL, Warfield KL, Bavari S, Klaenhammer TR (2005) Lactobacilli activate human dendritic cells that skew $\mathrm{T}$ cells toward $\mathrm{T}$ helper 1 polarization. Proc Natl Acad Sci 102:2880-2885

Morita H, He F, Fuse T, Ouwerhand AC, Hashimoto H, Hosoda M, Mizumachi K, Kurisaki J (2002) Cytokine production by the murine macrophage cell line J774.1 after exposure to Lactobacilli. Biosci Biotechnol Biochem 66:1963-1966

Paoletti R, Bolego C, Poli A, Cignarella A (2006) Metabolic syndrome, inflammation and atherosclerosis. Vasc Health Risk Manag 2:145-152

Pavan S, Desreumaux P, Mercenier A (2003) Use of mouse models to evaluate the persistence, safety, and immune modulation capacities of lactic acid bacteria. Clin Diagn Lab Immunol 10:696-701

Pena JA, Rogers AB, Ge Z, Ng V, Li SY, Fox JG, Versalovic J (2005) Probiotic Lactobacillus spp. diminish Helicobacter hepaticusinduced inflammatory bowel disease in interleukin-10-deficient mice. Infect Immun 73:912-920

Peran L, Camuesco D, Comalada M, Nieto A, Concha A, DiazRopero MP, Olivares M, Xaus J, Zarzuelo A, Galvez J (2005) Preventative effects of a probiotic, Lactobacillus salivarius ssp. salivarius, in the TNBS model of rat colitis. World J Gastroenterol 11:5185-5192

Perdigon G, Galdeano MC, Valdez JC, Medici M (2002) Interaction of lactic acid bacteria with the gut immune system. Eur J Clin Nutr 56:S21-S26

Pfaffl MW (2001) Development and validation of an externally standardised quantitative insulin like growth factor-1 (IGF-1) 
RT-PCR using LightCycler SYBR ${ }^{\circledR}$ Green I technology. In: Meuer S, Wittwer C, Nakagawara K (eds) Rapid cycle real-time PCR, methods and applications. Springer Press, Heidelberg, pp 281-291

Pfaffl MW, Horgan GW, Dempfle L (2002) Relative expression software tool (REST) for group-wise comparison and statistical analysis of relative expression results in real-time PCR. Nucleic Acids Res 30:e36

Pospiech A, Neumann B (1995) A versatile quick preparation of genomic DNA from gram-positive bacteria. Trends Genet 11:217-218

Rasmussen R (2001) Quantification on the LightCycler. In: Meuer S, Wittwer C, Nakagawara K (eds) Rapid cycle real-time PCR, methods and applications. Springer Press, Heidelberg, pp 21-34

Reilly N, Poylin V, Menconi M, Onderdonk A, Bengmark S, Hasselgren PO (2007) Probiotics potentiate IL-6 production in IL- $\beta$-treated Caco-2 cells through a heat shock-dependent mechanism. Am J Physiol Regul Integr Comp Physiol 293:R1169-R1179

REST: relative expression software tool (2009). http://rest.genequantification.info

Ringel-Kulka T, Palsson OS, Maier D, Carroll I, Galanko JA, Leyer G, Ringel Y (2011) Probiotic bacteria Lactobacillus acidophilus NCFM and Bifidobacterium lactis Bi-07 versus placebo for the symptoms of bloating in patients with functional bowel disorders: a double-blind study. J Clin Gastroenterol 45:518-525. doi:10.1097/MCG.0b013e31820ca4d6

Ruiz PA, Hoffmann M, Szcesny S, Blaut M, Haller D (2005) Innate mechanisms for Bifidobacterium lactis to activate transient proinflammatory host responses in intestinal epithelial cells after the colonization of germ-free rats. Immunology 115:441-450

Rutgeerts P, Van Assche G, Vermeire S (2004) Optimizing anti-TNF treatment in inflammatory bowel disease. Gastroenterology 126:1593-1610

Saegusa S, Totsuka M, Kaminogawa S, Hosoi T (2007) Cytokine responses of intestinal epithelial like Caco-2 cells to non pathogenic and opportunistic pathogenic yeasts in the presence of butyric acid. Biosci Biotechnol Biochem 71:2428-2434
Sanders ME, Klaenhammer TR (2001) The scientific basis of Lactobacillus acidophilus NCFM functionality as a probiotic. J Dairy Sci 84:319-331

Servin AL (2004) Antagonistic activities of lactobacilli and bifidobacteria against microbial pathogens. FEMS Microbiol Rev 28:405-440

Song Y, Kato N, Liu C, Matsumiya Y, Kato H, Watanabe K (2000) Rapid identification of 11 human intestinal Lactobacillus species by multiplex PCR assays using group and species-specific primers derived from the 16S-23S rRNA intergenic spacer region and its flanking $23 \mathrm{~S}$ rRNA. FEMS Microbiol Lett 187:167-173

Ukena SN, Westendorf AM, Hansen W, Rohde M, Geffers R, Coldewey S, Suerbaum S, Bue J, Gunzer F (2005) The host response to the probiotic Escherichia coli strain Nissle 1917: specific up-regulation of the proinflammatory chemokine MCP1. BMC Med Genet 6:43

Veckman V, Miettinen M, Matikainen S, Lande R, Giacomini E, Coccia EM, Julkunen I (2003) Lactobacilli and streptococci induce inflammatory chemokine production in human macrophages that stimulates Th1 cell chemotaxis. J Leukoc Biol 74:395-402

Vinderola G, Matar C, Perdigon G (2005) Role of intestinal epithelial cells in immune effects mediated by gram-positive probiotic bacteria: involvement of toll-like receptors. Clin Diagn Lab Immunol 12:1075-1084

Wiedermann CJ, Kiechl S, Dunzendorfer S, Schratzberger P, Egger G, Oberhollenzer F, Willeit J (1999) Association of endotoxemia with carotid atherosclerosis and cardiovascular disease: prospective results from the Bruneck Study. J Am Coll Cardiol 34:1975-1981

Xing Z, Gauldie J, Cox G, Baumann H, Jordana M, Lei XF, Achong MK (1998) IL-6 is an anti-inflammatory cytokine required for controlling local or systemic acute inflammatory responses. J Clin Invest 101:311-320. doi:10.1172/JCI1368 